\title{
Modeling and Simulation of Light Oil Production using Inflow Control Devices
}

\author{
Ramesh Timsina $^{1} \quad$ Nora C. I Furuvik ${ }^{2} \quad$ Britt M. E. Moldestad ${ }^{3}$ \\ ${ }^{1}$ Faculty of Technology, University college of Southeast Norway, Norway, timsinarames@gmail.com \\ ${ }^{2}$ Faculty of Technology, University college of Southeast Norway, Norway, nora.c.i.furuvik@usn.com \\ ${ }^{3}$ Faculty of Technology, University college of Southeast Norway, Norway, britt.moldestad@usn.com
}

\begin{abstract}
Light crude oil production is the most economical and is currently serving as benchmark together with medium crude oil. The most of the conventional oil fields in the worlds are either light or medium crude oil. Conventional inflow control devices (ICDs) are designed to delay water breakthrough but do not have the capability to control the water inflow after breakthrough. Autonomous inflow control devices (AICDs) are developed to choke the inflow of water after breakthrough has occurred.

Simulations is done by developing integrated transient wellbore-reservoir model in OLGA-Rocx. The specifications of the reservoir are specified in Rocx and the wellbore model is developed from the different modules available in OLGA. Simulations include fractured reservoir, heterogeneous reservoir and the homogeneous reservoir. The results show that autonomous inflow controllers have a higher potential to limit the water influx compared to the conventional ICDs.

The benefit of using AICDs was less significant in the homogenous reservoir than heterogeneous reservoir because of low frictional pressure drop along the well.

The functionality of the different inflow controllers for light oil reservoir is studied and results are compared.
\end{abstract}

Keywords: light oil production, inflow control devices, Oil and gas, water breakthrough, OLGA, Rocx, near well simulation

\section{Introduction}

One of the major challenges that the oil industry faces today is early water breakthrough and high production of water from mature oil fields. Early water breakthrough can occur due to high frictional pressure drop in the well or due to high permeability zones or fractures in the reservoirs. This causes reduction of the oil production. In fact, some of the wells are shut down because of excessive water production.

There are different types of inflow control devices (ICDs) developed for delaying breakthrough of water and gas. They are designed to improve completion performance, the overall efficiency and the lifetime of the wells.

Conventional ICDs are designed to delay water or gas breakthrough but do not have the capability to control the water inflow after breakthrough. So, there is no solution other than to choke the entire flow from the system after a certain time. Hence, there has been various development in this inflow control technologies with the autonomous operation. Autonomous inflow control device (AICD) chokes the fluid flow into the wellbore from the high permeable zone after the water breakthrough, allowing normal oil production from the other zones. This will enhance the well performance and increases the recovery of oil from existing reservoirs.

The oil reservoirs will show different behaviors at different conditions and this will affect the well performance. The objective of this work is to perform near well simulations of oil production from light oil reservoir using different types of ICDs with water drive. The studied ICDs include conventional ICDs and autonomous inflow controllers.

\section{Background}

Presently, the conventional oil, which is referred to as light or medium oil is the benchmark of the crude oil. The crude like West Texas Intermediate (WTI) (API = 39.6), brent crude (API = 38.06) and Dubai crude (API $=31$ ) serves as the benchmark crude across the globe. The light crude oil has low viscosity and flows freely at room temperature. It has low specific gravity because of low density. Light crude oils also have low wax content.

Heavy oils have low mobility due to its high viscosity. This makes transportation of heavy oils difficult. Extra costs will be added to make the heavy oil viable (Alomair et al, 2013). It is also important to optimize the oil production and recovery from light oil reservoirs.

\section{Inflow control technologies}

An ICD is a well completion device used to choke the fluid flow entering the base pipe from the annulus. It is a passive inflow control device, i.e. it does not have any 
active parts, which can be controlled or modified to regulate the flow through it. ICD adds up an additional pressure drop across the completion and restricts the inflow along the well. Generally, all the ICDs are selfregulating in nature, as the settings cannot be changed after installation (Torbergsen, 2010).

The higher flow rates from the high permeability zones cause early water breakthrough. The early water breakthrough can be delayed by having a higher flow restriction in high permeable zones. Further, ICD can produce at high rates from zones that have poorer production rate. This will increase the production and recovery (Fernandes et. al, 2009).

The common types of ICDs present in the industry use either friction or restriction to create a pressure drop across it. The most commonly used ICDs are presented in this section.

\subsection{Channel type ICD}

Figure 1 shows the schematics of the channel type ICD that uses surface friction to develop the desired pressure drop. The fluid passes through a multi-layered screen into the annulus and enters the wellbore through the channels. The fluid is forced to change its flow direction several times, causing a pressure drop across it. The chances of erosion and plugging are low because of low fluid velocity. Channel ICDs are dependent on fluid viscosity. So, a large difference in oil and water viscosity after water breakthrough can cause nonuniform inflow to the wellbore (Fernandes et. al, 2009).

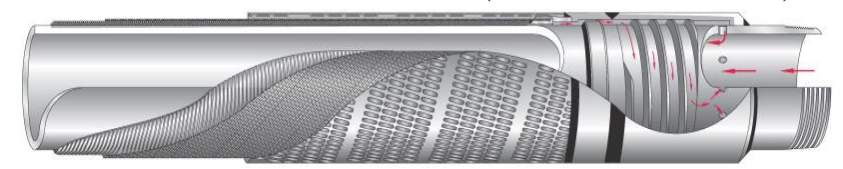

Figure 1. Channel ICD schematics (Birchenko et al, 2010)

\subsection{Orifice/nozzle type ICD}

Figure 2 shows the schematics of the orifice type of ICD that uses restriction of fluid flow to develop the desired pressure drop. Orifice ICDs are simple in design where the fluid passes through small diameter nozzles or orifices that create resistance. The pressure drop across the orifice ICD is instantaneous and is highly dependent on the density and velocity of the fluid. An orifice ICD is likely to have high sand erosion rate.

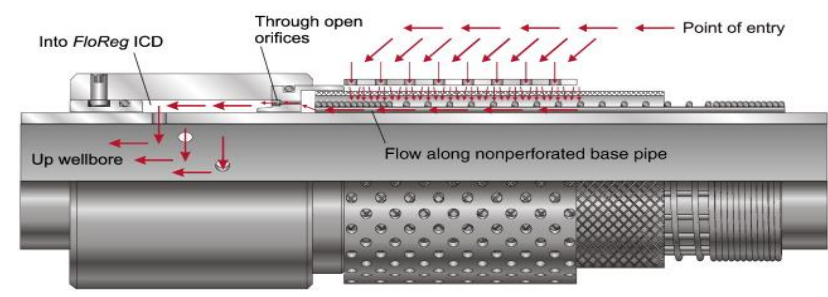

Figure 2. Orifice ICD schematics (Birchenko et al, 2010)

The pressure drop across an orifice can be expressed by:

$$
\nabla P=C \cdot \frac{1}{2} \cdot \rho \cdot v^{2}
$$

Where, $\mathrm{C}$ is the geometrical constant, $\rho$ is the fluid density and $v$ is the fluid velocity. This type of ICD is not dependent on fluid viscosity, thus ideal for applications where the viscosity sensitivity is low (Fernandes et. al, 2009).

According to Fernandes et al., an ICD can work effectively when the frictional pressure drop across the wellbore is relatively high compared to the drawdown pressure. Fractured reservoir with long wells also favors the ICDs installations (Fernandes et. al, 2009).

ICD is a passive device and cannot choke for water or gas breakthrough occurs. The oil industry has therefore focused on developing new technology for choking of such unwanted fluids. Inflow control valves (ICVs) are the example of this development. ICVs are active sliding sleeve valves, operated remotely by means of a controlling system. The electrical connection to the control room favors only for short wells. But the unpredicted reservoir behavior favors ICVs for higher recovery compared to ICDs. ICVs have flexible operation with the change in the operating conditions. ICVs are more expensive than ICDs as they have moving parts. ICDs are simple and have low installation risks as they do not have any moving parts, (Al-Khelaiwi et al, 2010).

There has been new development on these ICVs to adjust the inflow autonomously. Autonomous technology can adjust their performance based on the wellbore dynamics. Autonomous inflow control device (AICD) are being developed by companies like Halliburton, Statoil and others. The autonomous inflow control device developed by Statoil is called Rate Controlled Production (RCP) devices. RCP is capable of that choking for low viscous fluids, and is allowing high viscous fluid to flow through it without any restriction (Halvorsen et al, 2012). The AICD developed by Inflow control AS is called Autonomous inflow control valve (AICV). AICV is capable to restrict the influx of unwanted fluids. AICV can shut off unwanted fluids autonomously when there is viscosity change in the fluids.

\section{Development of OLGA Rocx model}

A simulation model was developed using OLGA-Rocx. The methodology adopted to build this dynamic reservoir-wellbore model is described along with a selection of different input parameters for the model.

\subsection{Reservoir (Rocx) model}

The reservoir dimensions are listed in Table 1. The length is divided into 10 sections $(99.2 \mathrm{~m})$ with one AICD in each section. This is the equivalent AICD, representing 8 normal AICDs $(12.4 \times 8=99.2 \mathrm{~m})$. Generally, the normal AICDs are installed at a length of $12.4 \mathrm{~m}$ of well 
Table 1. Dimension of the reservoir

\begin{tabular}{|l|l|}
\hline Reservoir & Span $(m)$ \\
\hline Length $(\mathrm{x})$ & 992 \\
\hline Width (y) & 80 \\
\hline Height (z) & 20 \\
\hline
\end{tabular}

The horizontal well is located along the $\mathrm{x}$-direction. The well location in $\mathrm{y}-\mathrm{z}$ plane is shown in Figure 3.

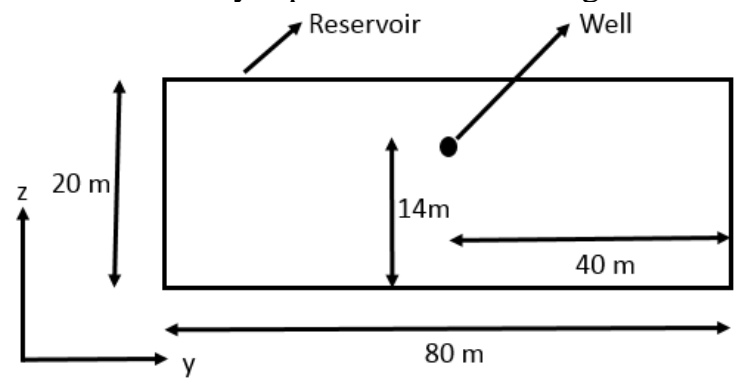

Figure 3. Location of the well in yz plane

The computational simulation should be accurate and time efficient. Finer grids and small-time steps give more accurate results but require a significant amount of time as well as computational resources. Finer mesh towards the well in y-direction was chosen with 29 elements. The simulation was done for 10 equivalents AICDs, hence the length was divided into 10 elements of constant size and the height was divided into 10 elements of constant size. The developed grid in threedimension is shown in Figure 4.

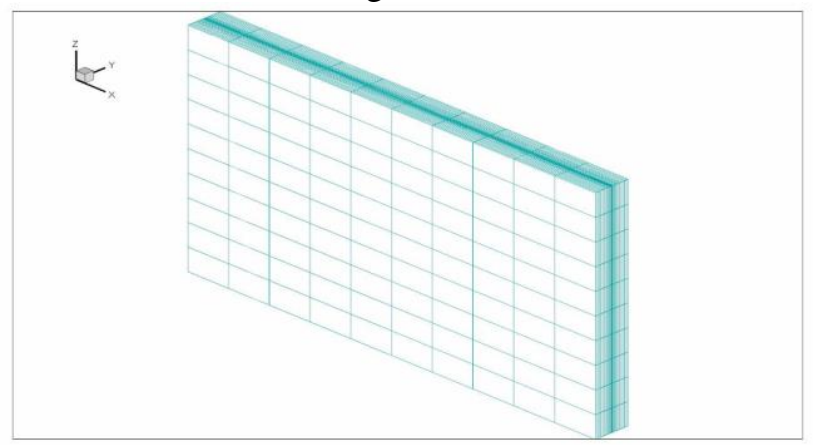

Figure 4. 3-D view of the grid

\subsection{Fluid Properties}

It is essential to know the Pressure Volume Temperature (PVT) relation of the fluids that is being used in simulations. The crude oils have a wide range of physical and chemical properties. One of the models used to estimate the PVT relations is the black oil fluid model. The black oil fluid model is a model that assumes that the oil components will always be in the liquid phase and does not evaporate at any conditions. The reservoir temperature is significantly lower than critical temperature and reservoir pressure is more than cricondenbar.
The black oil model was selected over the PVT table model in Rocx. The basic properties of light oil used for the simulation are presented in Table 2. These values were considered at measured reservoir temperature of $100^{\circ} \mathrm{C}$ and pressure of $130 \mathrm{bar}$.

Table 2. Oil properties used for simulations

\begin{tabular}{|l|l|}
\hline Oil viscosity $(\mathrm{cP})$ & 3 \\
\hline Oil specific gravity & 0.85 \\
\hline Gas specific gravity & 0.64 \\
\hline GOR $\left(\mathrm{Sm}^{3} / \mathrm{Sm}^{3}\right)$ & 150 \\
\hline
\end{tabular}

This simulation was done with the bottom water drive. So, for simulation with water drive, two feed streams were defined for oil and water. These feed streams are presented in Table 3.

Table 3. Feed streams

\begin{tabular}{|l|l|l|l|}
\hline Stream & Fraction type & Fraction & Watercut \\
\hline Oil & GOR & 150 & 0.0001 \\
\hline Water & GLR & 0.0001 & 0.99 \\
\hline
\end{tabular}

\subsection{Reservoir properties}

The porosity of the reservoir was taken as 0.3 and is constant throughout the reservoir. The permeability in each direction was defined by giving a value for each block in the reservoir in the respective direction. The simulated reservoir model based on the permeability profile were as follows:

- Fractured reservoir with a very high permeable zone

- Heterogenous reservoir with one relatively high permeable zone and with one relatively low permeable zone

- Homogenous reservoir

The horizontal permeability was taken as 10 times higher than the vertical permeability in each block of the reservoir. The vertical permeability profiles of these reservoirs are shown in Figure 5.

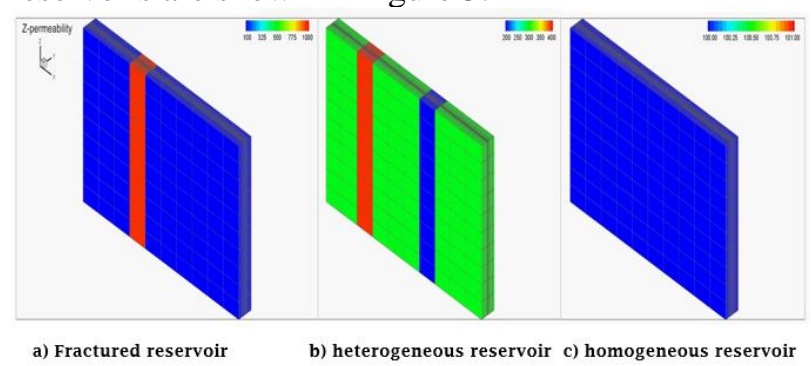

Figure 5. Vertical permeability profile

\subsection{Simulation}

Initially, the black oil feed was defined as $100 \%$ oil and the reservoir were fully saturated with oil. The reservoir 
temperature is $100^{\circ} \mathrm{C}$ and the reservoir pressure is 130 bar.

The boundary conditions are defined according to the well location in the reservoir. The feed is defined as the oil feed flowing in $\mathrm{x}$-direction. The bottom water drive is defined accordingly and the main direction of flow is set in z-direction. The water drive temperature and pressure were also set to $100^{\circ} \mathrm{C}$ and $130 \mathrm{bar}$ and the main direction of flow in the reservoir is set along $\mathrm{z}$ direction.

The simulation was performed using a linear iterative solver named 'Linsolver'. The minimum time step was set to 100 s and the maximum time step to 3600 s, with an initial time step of $0.01 \mathrm{~s}$.

\subsection{Development of wellbore model}

Two pipes are taken to represents the well (Flowpath) and the annulus (Pipeline) of the flow system. The length of the well is $992 \mathrm{~m}$ and diameter is $0.1 \mathrm{~m}$. The surface roughness was set to $5 \times 10^{-05} \mathrm{~m}$ and is divided into ten zones. Each zone is further divided into two sections. The details of two sections are presented in Figure 6.

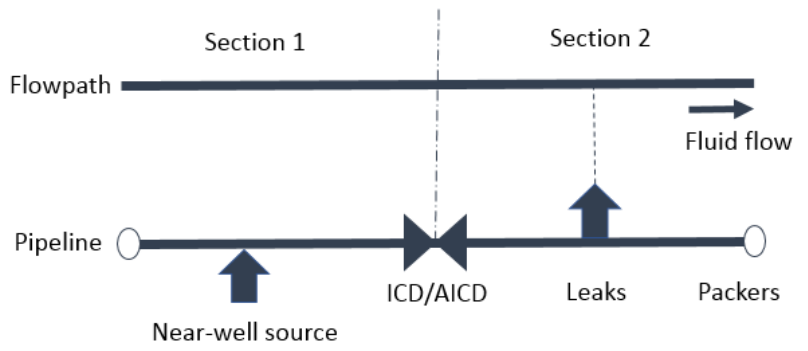

Figure 6. Representation of single zone of well

The inflow from the reservoir source (Near-well source) enters the pipeline from section 1 . Then this fluid passes through the inflow controllers into section 2. Now, this fluid enters the Flowpath at section 2 from the pipeline via leaks. The different zones of annulus were separated by means of a closed valve (opening $=0$ ) which represents a packer. This packer ensures that there is no flow between the zones in the annulus section. Finally, the fluid from each zone is collected in the well and moves towards the heel section of the wellbore. The OLGA modules that were used to develop this model are presented in Table 4.

Table 4. Components used in OLGA

\begin{tabular}{|l|l|l|}
\hline Components & $\begin{array}{l}\text { OLGA } \\
\text { module }\end{array}$ & \multicolumn{1}{c|}{ Description } \\
\hline $\begin{array}{l}\text { Inflow } \\
\text { source }\end{array}$ & $\begin{array}{l}\text { Nearwell } \\
\text { source }\end{array}$ & $\begin{array}{l}\text { Coupled with reservoir } \\
\text { model (Rocx file) }\end{array}$ \\
\hline Leak & Leak & $\begin{array}{l}\cdot \text { Diameter }-35 \mathrm{~mm} \\
\mathrm{CD}^{1}-1\end{array}$ \\
\hline
\end{tabular}

\begin{tabular}{|c|c|c|}
\hline & & $\begin{array}{l}\text { - No mass transfer } \\
\text { between the phase } \\
\text { - Connects to the } \\
\text { Flowpath }\end{array}$ \\
\hline ICD & Valve & $\begin{array}{l}\text { - Diameter }-20 \mathrm{~mm} \text {, } \\
\mathrm{CD}-0.84 \\
\text { - The diameter of the } \\
\text { valve was used to } \\
\text { decide the required } \\
\text { pressure drop. }\end{array}$ \\
\hline AICD & $\begin{array}{l}\text { Valve/PID } \\
\text { controller }\end{array}$ & $\begin{array}{l}\text { - Diameter }-20 \mathrm{~mm} \text {, } \\
\mathrm{CD}-0.84, \\
\text { - The valve opening } \\
\text { was controlled by a } \\
\text { PID controller }\end{array}$ \\
\hline Packers & Valve & $\begin{array}{l}\text { - Diameter }-0.1 \mathrm{~m} \text {, } \\
\text { opening }-0 \text { (fully } \\
\text { closed) }\end{array}$ \\
\hline
\end{tabular}

The boundary conditions at the end of Flowpath (heel) is set to 120 bar and $100 \mathrm{C}$.

The AICD is a valve module controlled by a PID controller module. The control variable for this PID controller was in situ water cut percentage (75\%) which was transmitted to the PID controller by the transmitter module in OLGA. The parameters of the PID controller are defined in Table 5.

Table 5. PID controller parameters

\begin{tabular}{|l|l|}
\hline Parameter & Value \\
\hline Amplification & -0.01 \\
\hline Bias (Initial signal) & 1 \\
\hline Integral constant [s] & 50 \\
\hline Maximum signal & 1 \\
\hline Minimum opening & 0.01 \\
\hline
\end{tabular}

\subsection{Simulated cases}

The three-main type of reservoir mentioned in Figure 5 are simulated with different inflow control technologies. The simulated types of inflow control technologies are presented in Table 6 .

Table 6. Types of simulated inflow control technologies

\begin{tabular}{|l|l|}
\hline ICD & $\begin{array}{l}\text { Wells with ICDs (Diameter }-20 \mathrm{~mm}, \mathrm{CD} \\
-0.84)\end{array}$ \\
\hline AICD & $\begin{array}{l}\text { Wells with AICDs (Diameter }-20 \mathrm{~mm}, \\
\mathrm{CD}-0.84)\end{array}$ \\
\hline ICDres & $\begin{array}{l}\text { ICD with relatively high flow restriction at } \\
\text { the high permeable zone (Diameter - } \\
0.2 \mathrm{~mm} \text { ) and normal ICDs (Diameter - 20 } \\
\mathrm{mm} \text { ) in the rest of the zones }\end{array}$ \\
\hline
\end{tabular}

\footnotetext{
${ }^{1}$ Coefficient of Discharge
} 


\section{Simulation results}

This chapter contains the simulation results for the different cases.

\subsection{AICD and ICD performance in fractured reservoir}

The accumulated oil and water are presented in Figure 7 for the cases mention in Table 6 .
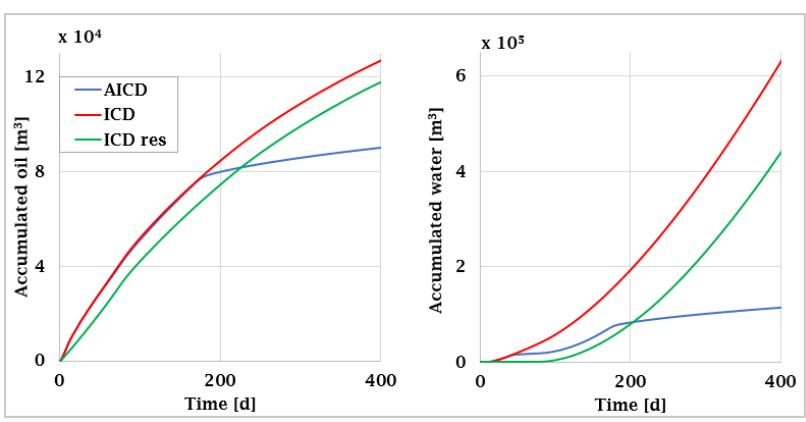

Figure 7. Accumulated liquid for fractured reservoir

The case with AICD has the highest potential to reduce the water accumulation among the considered inflow control technologies. The ICD case with restriction gives less accumulation of water compared to normal ICDs. The accumulated oil and water volume with different inflow control technologies are presented in Table 7. The results are obtained after 400 days of production.

Table 7. Accumulated liquids

\begin{tabular}{|l|l|l|}
\hline Case & $\begin{array}{l}\text { Accumulated oil } \\
{\left[\mathrm{m}^{3}\right]}\end{array}$ & $\begin{array}{l}\text { Accumulated water } \\
{\left[\mathrm{m}^{3}\right]}\end{array}$ \\
\hline ICD & 127145 & 634733 \\
\hline AICD & 89943 & 113654 \\
\hline ICDres & 118123 & 441054 \\
\hline
\end{tabular}

These data show that the well with non-uniform ICDs can be a good choice to reduce the accumulated water. The restriction imposed on the high permeability zones, reduces the water accumulation by $30 \%$ compared to normal ICDs. However, the autonomous device gives remarkably higher potential of reducing the water influx. The AICDs produces $82 \%$ less water compared to the normal ICDs.

The use of both AICD and the non-uniform ICD have decreased the water production as well as oil production. As both AICD and non-uniform ICD have reasonable potential to control water inflow causing a slight change in oil production, they have to be studied further depending on the types of applications.

The liquid flow rates with different inflow control technologies for the fractured reservoir are presented in Figure 8. There are significant changes in the oil and water flow rates throughout the production time. This illustrates the features of the different inflow controllers.

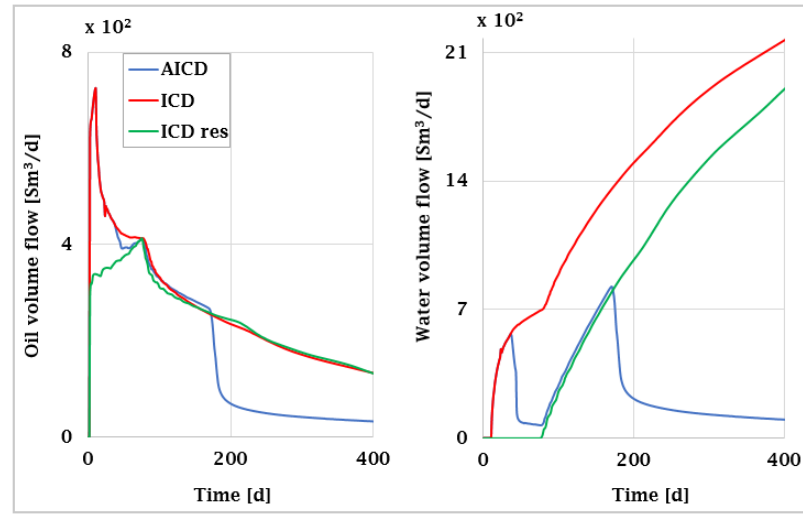

Figure 8. Liquid flow rates for fractured reservoir

According to Figure 8, initial water breakthrough occurs on day 9 of production for the cases with AICD and normal ICD. Once the water is produced, the oil volume flow rate decreased significantly.

By installing a higher restrictive ICD with higher pressure drop, in the high permeable zone, the first water breakthrough has been delayed to 76 days of operation which is the same as the second water breakthrough for the two other cases. The oil production has also been reduced due to the introduction non-uniform ICDs. Table 8 shows the accumulated oil after the first and second water breakthrough.

Table 8. Oil production at breakthroughs

\begin{tabular}{|l|l|l|}
\hline Case & $\begin{array}{l}\text { Accumulated oil } \\
\text { after } 1^{\text {st }} \\
\text { breakthrough }\left[\mathrm{m}^{3}\right]\end{array}$ & $\begin{array}{l}\text { Accumulated oil } \\
\text { after } 2^{\text {nd }} \\
\text { breakthrough }\left[\mathrm{m}^{3}\right]\end{array}$ \\
\hline ICD & $6889[9$ days $]$ & $42116[76$ days $]$ \\
\hline ICDres & $32979[76$ days $]$ & - \\
\hline AICD & $6889[9$ days $]$ & $41005[76$ days $]$ \\
\hline
\end{tabular}

The accumulated oil with AICD is slightly less than that of normal ICD at the time of the second breakthrough because of the closure of the autonomous device in the fractured zone. It can be seen that the non-uniform ICD model has the capability to delay water breakthrough by 67 days in this reservoir. This is the most positive features of this model, while its inability to restrict water influx after breakthrough is the drawback. It is challenging to find the precise location of the high permeable zone, and therefore there would be a high risk installing restrictive ICDs.

Figure 8 shows that the restrictive ICD model has been able to delay the water breakthrough significantly. However, the accumulated water goes on increasing after breakthrough occurred. This indicates that the autonomous model has large benefits compared to other models. 


\subsection{AICD and ICD performance in homogeneous reservoir}

The liquid flow rates for the homogeneous reservoir with vertical permeability of $1000 \mathrm{mD}$ are presented in Figure 9.

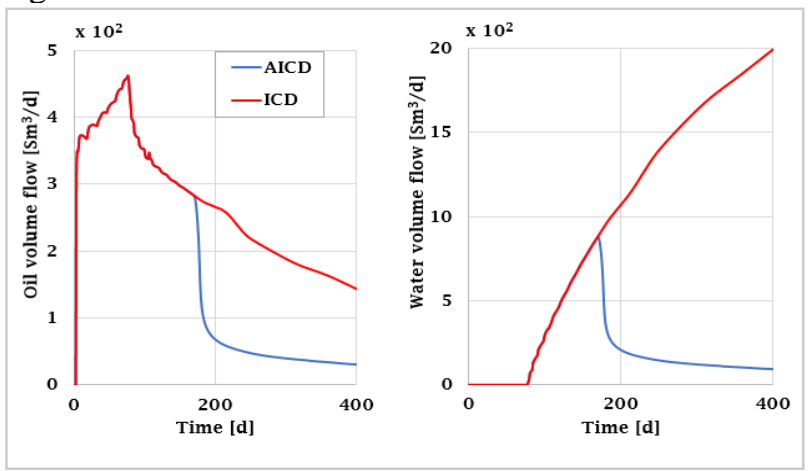

Figure 9. Liquid flow rates for homogeneous reservoir

The oil volume flow increases continuously and reaches $456 \mathrm{Sm}^{3} / \mathrm{d}$ just before the water breakthrough. After the water breakthrough at 75 days, the oil volume flow decreases and the water volume flow increases. There has been a continuous decrease of the oil flow rate and increase of the water flow rate after breakthrough for the ICD case. The flow rates for the AICD case are heavily reduced after closing of the valves.

The frictional pressure drop along the wellbore was observed to be around 0.2 bar just before the water breakthrough. The rather low frictional pressure drop causes water breakthrough at about same time in all the zones. The use of the autonomous device is not so significant because of closure of all the AICDs within a short time interval.

Figure 10 shows the accumulated liquids for the homogeneous reservoir.

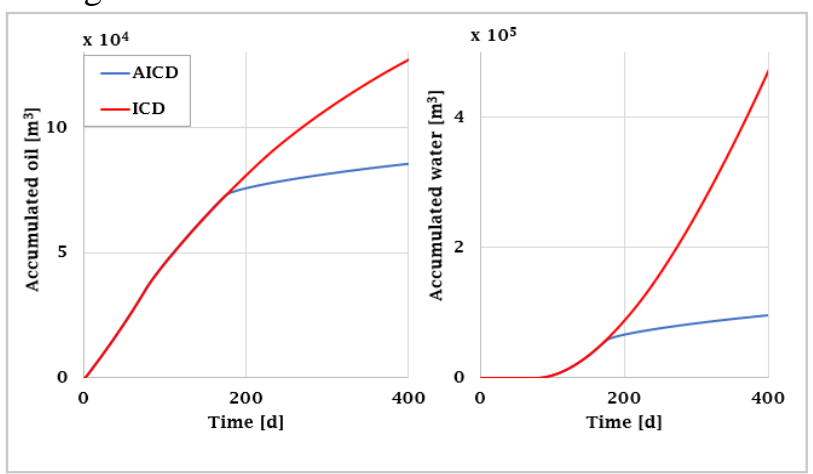

Figure 10. Accumulated liquid for homogeneous reservoir

There has been a continuous increment of the accumulated oil with ICD while it drops for the case with AICD after closing the valves. Once the water breakthrough has started, accumulated water is also increasing continuously for the ICD. The autonomous inflow controllers are able to reduce the water significantly. Although there has been a reduction in accumulated oil, the accumulated water reduces by $80 \%$ with the use of autonomous devices.

\subsection{AICD and ICD performance in heterogeneous reservoir}

An intermediate reservoir between the homogeneous and fractured reservoir was also simulated. It has one zone with relatively high permeability and one zone with relatively low permeability compared to the rest of the zones. The liquid flow rates at standard conditions are presented in Figure 11.

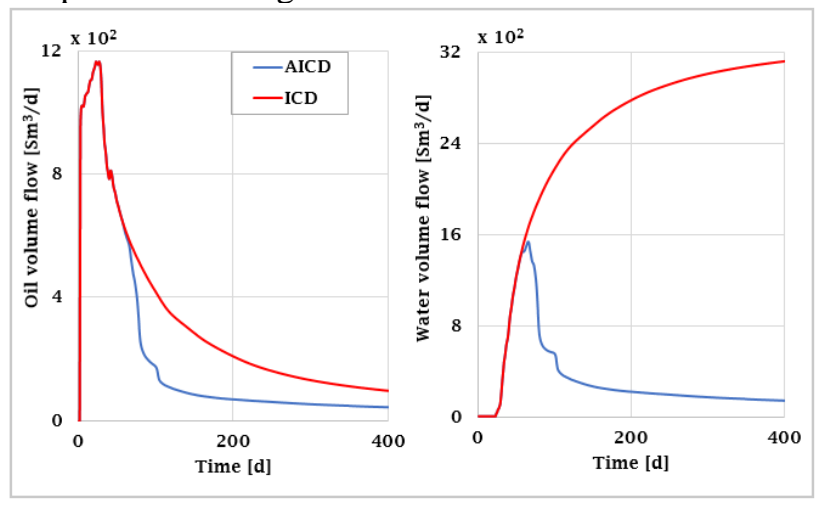

Figure 11. Liquid flow rates for heterogeneous reservoir

The plots show that the oil volume flow reaches a maximum value of $1156 \mathrm{Sm}^{3} / \mathrm{d}$ and decreases considerably once the water breakthrough has occurred. The water breakthrough occurred on day 25 from the start of the operation. The closing of the first valve is in the high permeability zone.

There is a reduction of liquid flow rates after the autonomous devices have been shut off. The water volume flow increases continuously and reaches around $3200 \mathrm{Sm}^{3} / \mathrm{d}$ with the use of ICD. This, in turn, gives high accumulation of water as presented in Figure 12.

Figure 12 shows the accumulation of oil and water for the heterogeneous reservoir. The accumulation of oil is reduced with the use of autonomous devices compared to that of ICDs. However, the accumulation of water decreases significantly by around $88 \%$ after 400 days of operation.

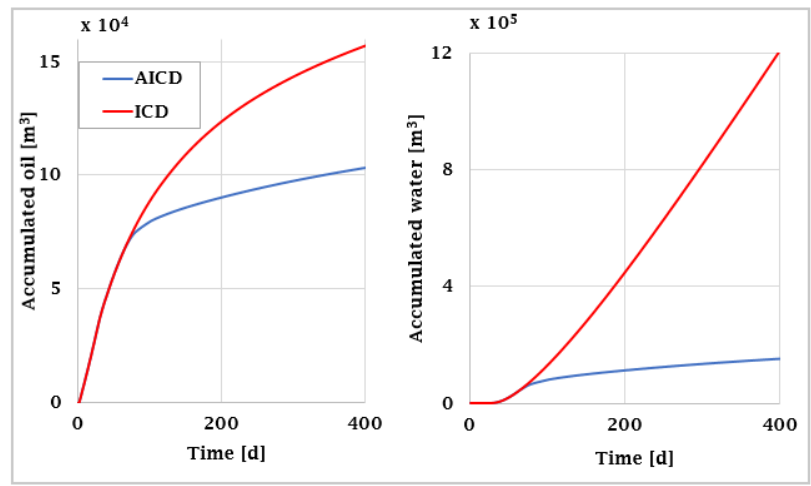

Figure 12. Accumulated liquid for heterogeneous reservoir 


\subsection{Effects of different model parameters}

\subsubsection{Oil viscosity}

This simulation was performed to see the effect of changing the oil viscosity in the model. Light oils with oil viscosity of $3 \mathrm{cP}, 1.5 \mathrm{cP}$, and $0.8 \mathrm{cP}$ were studied. The simulations were done with AICD for light oil in the fractured reservoir. The oil and water flow rates at standard condition are presented in Figure 13.

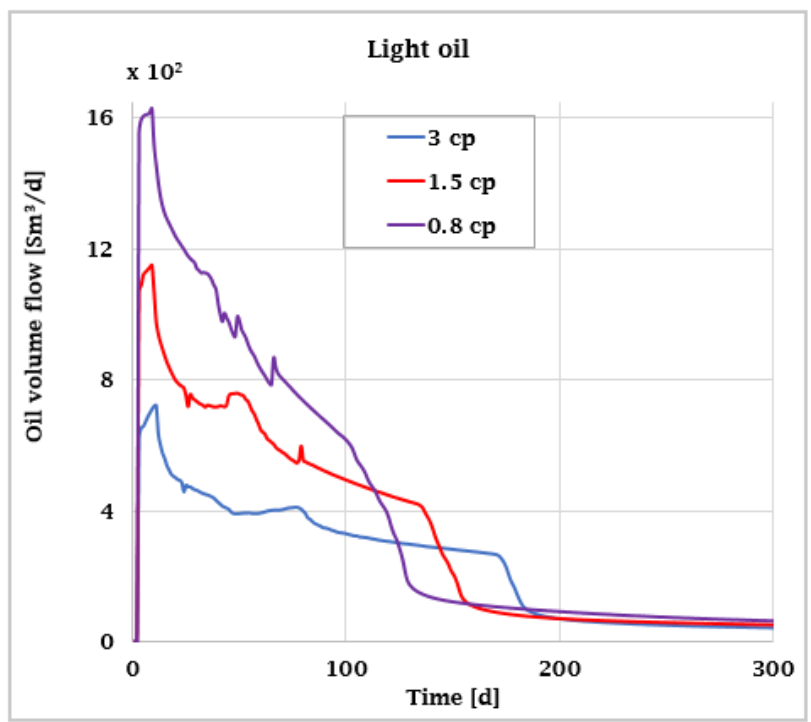

Figure 13. Oil volume flow with different oil viscosity

The graphs show that the oil volume flow increases with the decrease of oil viscosity. The water breakthrough was observed earlier for the lesser light oil. The oil volume flow for the less light oil decreases more compared to others after water breakthrough. by:

The mobility ratio of oil with respect to water is given

$$
M=\frac{k_{r w}}{\mu_{w}} \cdot \frac{\mu_{o}}{k_{r o}}
$$

This shows that, for a constant relative permeability of oil, water, and constant viscosity of water inside a reservoir, the mobility ratio is directly proportional to oil viscosity. As the oil viscosity decreases, the mobility ratio will decrease. And the expression for the definition of mobility ratio is given by:

$$
M=\frac{\text { mobility of water }}{\text { mobility of oil }}
$$

Hence, the mobility of oil increases with the reduction of the mobility ratio. This is illustrated in Figure 13 The oil volume flow after the closing of the autonomous valves is almost the same for all the cases as they all have the same minimum opening when the valve is in closed positions.

\subsubsection{Mesh size}

This study was done to see the effects of changing the mesh size of the simulated reservoir. It can be argued that the finer grid gives more accurate results than the coarse grid. The grid along the y-direction was already finer close to the wellbore. It is interesting to see the results with finer grids in the $\mathrm{x}$-direction also. Therefore, the mesh size in the $\mathrm{x}$-direction is reduced to half the original size. This simulation was done with AICD for light oil in the fractured reservoir. Figure 14 shows the liquid flow rates at standard conditions with two different mesh sizes along the flow direction.

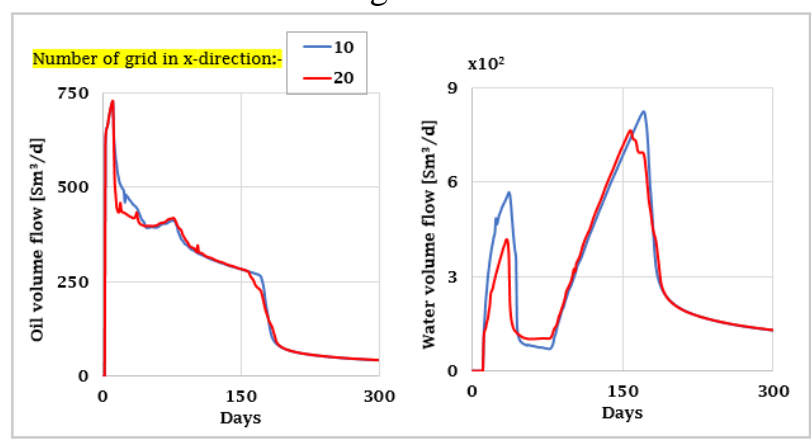

Figure 14. Oil and water flow rates for different mesh sizes

The flow rates with the increased number of grids deviate slightly from that of the normal grid. The oil volume flow is slightly different particularly during the closure of autonomous devices. The flow rates with 20 grids show closer overview of actual flow rates during this period. The water volume flow rate before the closure of the valves drop slightly from each other. However, the flow rates after the closure of AICD is the same for both the cases. It can be argued that the overall flow rate is insignificantly sensitive to the mesh sizes which is the good features of this model.

\section{Conclusion}

Near-well simulations using the OLGA-Rocx simulation software are performed during this study. Early water breakthrough occurred due to the fractures or the heterogeneity in the reservoirs. The water breakthrough from the fractured, heterogeneous and homogenous light oil reservoirs is observed after 9, 25 and 75 days of production respectively.

The non-uniform ICDs has the ability to delay the early water breakthrough. The restriction introduced on an ICD at the high permeable zone of the light oil reservoir is able to delay the initial water breakthrough from day 9 to day 76. The main drawback of this case is the high installation risks as it is difficult to pre-locate the fractured zones inside a reservoir. The restrictive ICD will reduce the oil production if installed in zones other than the high permeable zones.

The frictional pressure drop along the well is around 0.1 bar for homogeneous reservoir causing almost same production in all zones of the well. The water 
breakthrough occurred at about same time along the whole well and all the AICDs closed during a short time interval. Therefore, the effects of AICDs are less significant in the homogeneous reservoir.

From the above simulations results, water accumulation can be reduced by the use of AICDs or the non-uniform ICDs. After a specified amount of water associated with the flow, AICD choked the total flow entering the wellbore. AICDs are better to limit the water accumulation and the water production was reduced with $88 \%$ compared to the normal ICDs in the heterogeneous reservoir. The water accumulation in the fractured reservoir reduced significantly by around $82 \%$ and oil accumulation by $29 \%$ by the use of AICD compared to normal ICDs. The production from the high permeability zones is choked locally by using AICDs, allowing normal oil production from the other zones. Therefore, AICDs are better suited for heterogeneous and fractured reservoirs.

The oil volume flow increased with the decrease of oil viscosity. This is due to the higher mobility of oil. For the same relative permeability, there is around $47 \%$ increase in oil flow rate with the decrease of oil viscosity from $3 \mathrm{cP}$ to $1.5 \mathrm{cP}$ and $120 \%$ increase in oil flow rate with the decrease of oil viscosity from $3 \mathrm{cP}$ to $0.8 \mathrm{cP}$ after 10 days. The oil volume flow and water volume flow are almost the same with doubling the number of the grid along the well. Thus, confirming that the developed model is insignificantly sensitive to the mesh sizes in the well direction.

This study shows that the oil reservoirs behaves different at different reservoir conditions. The functionalities of different inflow controllers are different and show their unique characteristics.

\section{Acknowledgements}

This study was done as a part of the master's program in Process Technology in University college of Southeast Norway during spring 2017. The University college provided all the necessary software arrangement during the study.

$\begin{array}{ll}\text { Abbreviations } \\ \text { AICD } & \text { Autonomous Inflow Control Device } \\ \text { API } & \text { American Petroleum Institute } \\ \text { ICD } & \text { Inflow Control Device } \\ \text { ICV } & \text { Inflow Control Valve } \\ \text { GLR } & \text { Gas Liquid Ratio } \\ \text { GOR } & \text { Gas Oil Ratio } \\ \text { WTI } & \text { West Texas Intermediate }\end{array}$

\section{References}

Al-Khelaiwi F. T., Birchenko V. M., Konopczynski M. R. and Davies D. R. Advanced wells: a comprehensive approach to the selection between passive and active inflow-control completions. SPE Production \& Operations, vol. 25 no. 03, pp 305-326, 2010. doi: 10.2118/132976-PA

Alomair A. Osamah and Almusallam S. Abdulwahab. Heavy crude oil viscosity reduction and the impact of asphaltene precipitation. Energy \& Fuels, vol. 27, no. 12, pp. 7267-7276, 2013.

Birchenko V. M., Muradov K. M. and Davies D. R. Reduction of the horizontal well's heel-toe effect with inflow control devices. Journal of Petroleum Science and Engineering, vol. 75 no. 1, pp. 244-250, 2010. doi: 10.1016/j.petrol.2010.11.013

Fernandes X. Preston, Li Zhuoyi and Zhu Ding. Understanding the roles of inflow-control devices in optimizing horizontal-well performance. SPE Annual Technical Conference and Exhibition, 2009, Society of Petroleum Engineers. doi: 10.2118/124677-MS

Halvorsen Martin, Elseth Geir, and Naevdal M. Olav. Increased oil production at Troll by autonomous inflow control with RCP valves. SPE Annual Technical Conference and Exhibition, 2012, Society of Petroleum Engineers. doi: 10.2118/159634-MS

Torbergsen H.-E. Bensnes. Application and design of passive inflow control devices on the Eni Goliat oil producer wells. University of Stavanger, Norway, 2010. 